\title{
Characterization of the Occult Hepatitis B Virus Variants Circulating among the Blood Donors from Eastern India
}

\author{
Avik Biswas, ${ }^{1}$ Rajesh Panigrahi, ${ }^{1,2}$ Partha Kumar Chandra, ${ }^{1,2}$ Arup Banerjee, \\ Sibnarayan Datta, ${ }^{1,4}$ Manisha Pal, ${ }^{5}$ Subhashish Chakraborty, ${ }^{6}$ Prasun Bhattacharya, ${ }^{7}$ \\ Sekhar Chakrabarti, ${ }^{8}$ and Runu Chakravarty ${ }^{1}$ \\ ${ }^{1}$ ICMR Virus Unit, Kolkata, GB 4, 1st Floor, ID \& BG Hospital Campus, 57 Dr. Suresh Chandra Banerjee Road, Kolkata 700010, India \\ ${ }^{2}$ Tulane University Health Sciences Center, Department of Pathology and Laboratory Medicine, 1430 Tulane Avenue SL-79, \\ New Orleans, LA 70112-2699, USA \\ ${ }^{3}$ Translational Health Science and Technology Institute (THSTI), Gurgaon, Haryana 122016, India \\ ${ }^{4}$ Defence Research Laboratory, Tezpur, Assam 784001, India \\ ${ }^{5}$ Department of Statistics, University of Calcutta, Kolkata 700019, India \\ ${ }^{6}$ Institute of Blood Transfusion Medicine and Immunohematology, Kolkata 700006, India \\ ${ }^{7}$ Medical College \& Hospital, Kolkata 700073, West Bengal, India \\ ${ }^{8}$ National Institute of Cholera and Enteric Diseases, Kolkata 700010, India
}

Correspondence should be addressed to Runu Chakravarty; runugc@gmail.com

Received 28 August 2013; Accepted 23 September 2013

Academic Editors: H. L. Y. Chan and M. I. Lusida

Copyright (C) 2013 Avik Biswas et al. This is an open access article distributed under the Creative Commons Attribution License, which permits unrestricted use, distribution, and reproduction in any medium, provided the original work is properly cited.

\begin{abstract}
A previous study from West Bengal documented very high rate of occult $\mathrm{HBV}$ infection (OBI) among the HBsAg negative blood donors. This study was aimed to characterize the OBI strains circulating among the blood donors and to estimate the risk associated with the prevailing viral variants/mutants. Blood samples from 2195 voluntary blood donors were included in the study. HBsAg, $\mathrm{HBeAg}$, anti-HBc, and anti-HBs statuses of the samples were done by ELISA based detection. PCR amplification and sequencing were done to determine HBV genotypes, basal core promoter (BCP), and precore (Pre-C) mutations. Among the study samples, 268 were anti-HBc positive/HBsAg negative, among which 65 (24.25\%) were HBV DNA positive. Phylogenetic analysis revealed the presence of HBV/D (87.23\%), HBV/A (8.51\%), and HBV/C (4.26\%) $(P<0.0001)$. HBV/D3 (65.85\%) was the significantly prevalent subgenotype over HBV/D2 (26.83\%) and HBV/D1 (7.31\%) $(P=0.0003)$. Considerable prevalence of differential BCP $(1752 \mathrm{C}, 1753 \mathrm{C}$, $1762 \mathrm{~T} / 1764 \mathrm{~A}, 1753 \mathrm{C}+1762 \mathrm{~T} / 1764 \mathrm{~A}, 1773 \mathrm{C}$, and 1814C) and reverse transcriptase (rt) gene (rtI91L, rtL93P, rtS106C, rtR110G, rtN118T, rtS119T, rtY126H, rtG127W/R, rtC136R, and rtY158H) mutations was identified. Association of specific HBV subgenotypes with OBI was interesting and needs further study. Clinically relevant mutations were prevalent among the OBI strains which are of serious concern.
\end{abstract}

\section{Introduction}

The serological diagnosis of hepatitis B virus (HBV) infection is mainly based on hepatitis B surface antigen ( $\mathrm{HBsAg}$ ) detection assays, and the absence of HBsAg is believed to exclude infectivity. However, presence of HBV DNA in circulation/liver without detectable HBsAg, with or without the presence of any other HBV antibodies, is defined as occult HBV infection (OBI) [1].

The exact mechanism of OBI is still a matter of debate. Several different mechanisms are reported to be associated with OBI which includes mutations in S gene (specifically mutations in the major hydrophilic loop or in the "a" determinant region, which is the main target for antibodies used in diagnostic tests) that may alter HBsAg structure and expression; decrease of HBV replication and/or hindrance of HBsAg detection. However, some studies also showed that majority of occult HBV infections are caused by wild-type HBV strains [2].

So far, the clinical significance of OBI is largely unknown. Detection of OBI has been reported in subjects with clinical manifestations, such as chronic liver disease and 
hepatocellular carcinoma (HCC) [3]. Although most of the OBI carriers are asymptomatic, OBI has been detected in patients with cryptogenic chronic liver disease $[4,5]$ and could be associated with progression of liver fibrosis and cirrhosis development [3].

So far, up to ten genotypes (A through J) and several subgenotypes are identified and characterized [6-10], which show distinct geographical distribution pattern. There is growing evidence that genotypes influence the severity of liver diseases and also response to antiviral treatment [7, 11-13].

$\mathrm{HBV}$ mutant strains with mutations in the basal core region (BCP) and precore (pre-C) regions are studied, among which BCP double mutation (1762T/1764A) and pre-C stop codon mutations (1896A) are important. Other mutations in the $\mathrm{BCP}$ and pre-C region include $1752 \mathrm{C}, 1753 \mathrm{C}, 1757 \mathrm{~A}$, $1766 \mathrm{~T} / 1768 \mathrm{~A}$ double mutation, $1773 \mathrm{C}, 1814 \mathrm{C} / \mathrm{T}, 1858 \mathrm{C}, 1862 \mathrm{~T}$, $1888 \mathrm{~A}$, and 1899A. BCP double mutations are less frequent in asymptomatic carriers but are frequently detected in patients with HCC [14]. Additionally several studies reported mutations in the HBV reverse transcriptase (rt) domain leading to treatment failure $[15,16]$. A recent study documented the existence of HBVrt mutations among the chronic carriers of Eastern India [17].

So far, very few studies characterized the viral strains and viral genotypes circulating among the OBI positive individuals. A previous study from Eastern India reported very high rate of OBI among the voluntary blood donors [1]. But data regarding the frequency of clinically relevant $\mathrm{BCP} /$ pre$\mathrm{C}$ mutation and the rate of differential drug resistant HBVrt mutations are not there. Thus, this study was aimed to characterize the OBI strains circulating among the voluntary blood donors to determine the significance and the degree of risk factors associated with the different viral variants/mutants.

\section{Materials and Methods}

2.1. Study Subjects. A total of 2195 blood samples collected from the voluntary blood donors during the time period June 2006 to May 2009 were included in the study. Up to $3.0 \mathrm{~mL}$ of blood was collected, from which plasma/serum was separated and stored at $-80^{\circ} \mathrm{C}$ until further used. The study includes two projects approved by the respective institutional ethical committees. The informed signed consent of each donor prior to blood donation was also collected.

2.2. Serological Assays. HBsAg (HBsAg Uni-Form II; Hepanostika, Boxtel, The Netherlands), anti-HBc antibody (anti$\mathrm{HBc}$ total, i.e., both for IgM and IgG) (Hepanostika anti$\mathrm{HBc}$ Uni-form test, Biomerieux, The Netherlands), HBeAg (EQUIPAR, Varese, Italy), and the presence or absence of anti-HBs antibodies (Anti-HBs EIA, Diasorin, Saluggia, Italy) were determined.

After initial collection, all the samples were tested for the presence of anti-HBc antibody. Then, anti-HBc positive samples (after testing positive twice) were tested for $\mathrm{HBsAg}$ by ELISA. Anti-HBc(+ve)/HBsAg(-ve) samples were further tested for the presence of anti-HBs antibodies. All kinds of ELISA testing were done twice to confirm the findings.
2.3. Extraction of DNA from Plasma/Serum. From the anti$\mathrm{HBc}(+\mathrm{ve}) / \mathrm{HBsAg}(-\mathrm{ve})$ samples, DNA was extracted from $200 \mu \mathrm{L}$ of serum by using QIAamp DNA blood Mini Kit (Qiagen, Hilden, Germany). The final elution volume was $200 \mu \mathrm{L}$.

2.4. HBV DNA Detection, Quantification, PCR Amplification of Surface Gene Region, and Basal Core Promoter/Precore Region. Detection of the presence of HBV DNA was done by sensitive nested PCR amplification of HBV small surface gene region [18]. Additionally, the $\mathrm{HBV}$ surface gene PCR amplified samples were further amplified for $\mathrm{BCP} /$ pre-C gene region $[19,20]$. Precautions were taken during amplification process to protect against carry over contamination and false positive HBV DNA on PCR [21]. In addition, each sample was tested in duplicates, and negative controls were included during each assay. HBV DNA quantification was done by real time PCR detection assay as previously described [18].

2.5. HBV Genotyping/Subgenotyping and Cloning. PCR products are directly sequenced in both directions as previously described [22]. After sequencing, sequences were aligned by ClustalW multiple alignment programme, compared, and manually edited using BioEdit v7.0.4.1 program [23]. HBV genotypes and subgenotypes were assigned by phylogenetic analysis of surface gene region as previously described [22]. To verify the presence of minor subpopulations of virus pool, PCR product cloning was done as described previously [22].

The nucleotide sequences used in this study have been submitted to the DDBJ/EMBL/GenBank, accession numbers JQ388839-JQ388883.

2.6. Statistical Analysis. Statistical analysis of the data has been performed using MINITAB Statistical Software (version: 13.31, Minitab Inc., PA, USA). Frequency $\chi^{2}$-test has been used to examine association between two variables. Proportions have been tested wherever necessary. A $P$ value less than 0.05 has been considered as statistically significant.

\section{Results}

3.1. Baseline Characteristics of the Study Subjects. Among the 2195 collected blood samples, 268 were anti-HBc positive/HBsAg negative. Among these 268 anti-HBc positive/HBsAg negative cases 65, were positive for HBV DNA; thus, the rate of $\mathrm{OBI}$ among the anti-HBc positive population was $24.25 \%(65 / 268)$, and the overall OBI rate was $2.96 \%$ $(65 / 2195)$.

The demographic, serological, and virological characteristics of the 65 occult HBV infected blood donors are presented in the Table 1.

All the 268 anti-HBc positive/HBsAg negative samples were found to be negative for $\mathrm{HBeAg}$ serology.

3.2. HBV Genotype and Subgenotype Distribution. Initially, all the $65 \mathrm{HBV}$ DNA positive samples were targeted for sequencing analysis, but only 47 (47/65; 72.31\%) samples could be successfully sequenced for HBV partial surface gene 
TABLE 1: Demographic, serological, and virological characteristics of the 65 occult HBV positive blood donors.

\begin{tabular}{lc}
\hline Characteristics & HBsAg $(-) /$ antiH-Bc $(+)(n=268)$ \\
\hline HBV DNA positive (\%) & $65(65 / 268 ; 24.25 \%)$ \\
Age in years* (Mean \pm S.D.) & $33.92 \pm 10.46$ \\
ALT* (IU/L) $^{*}$ & $34.67 \pm 8.14$ \\
HBV viral load* & $3.78 \pm 0.80$ \\
(log $_{10}$ copies/mL) & $47(47 / 65 ; 72.31 \%)$ \\
\hline HBV genotype by & $4(4 / 47 ; 8.51 \%)^{\mathrm{a}}$ \\
sequencing $(\%)$ & $2(2 / 47 ; 4.26 \%)^{\mathrm{a}}$ \\
HBV/A & $41(41 / 47 ; 87.23 \%)^{\mathrm{a}}$ \\
HBV/C & $3(3 / 41 ; 7.31 \%)^{\mathrm{b}}$ \\
HBV/D & $11(11 / 41 ; 26.83 \%)^{\mathrm{b}}$ \\
D1 & $27(27 / 41 ; 65.85 \%)^{\mathrm{b}}$ \\
D2 & \\
D3
\end{tabular}

${ }^{*}$ Mean \pm Standard Deviation.

$P^{\mathrm{a}}<0.0001 ; P^{\mathrm{b}}=0.0003$.

region and analyzed for genotyping. Phylogenetic analysis of the sequences showed that three HBV genotypes are prevalent (namely, HBV/A, HBV/C, and HBV/D) (Figure 1). Overall, HBV/D was found to be the significantly predominant strain $(41 / 47 ; 87.23 \%)$, followed by HBV/A (4/47; 8.51\%) and HBV/C $(2 / 47 ; 4.26 \%)(P<0.0001)$ (Table 1 and Figure 2). For HBV/A and HBV/C, only one subgenotype could be identified (HBV/A1 (Aa) and $\mathrm{HBV} / \mathrm{Cl}(\mathrm{Cs})$, resp.). Among the HBV/D genotypes, three subgenotypes were prevalent, namely, HBV/D1 (3/41; 7.31\%), HBV/D2 (11/41; $26.83 \%)$, and HBV/D3 (27/41; 65.85\%). Among the different HBV subgenotypes identified, HBV/D3 was the significantly prevalent strain over HBV/D1 and HBV/D2 $(P=0.0003)$ (Figure 2).

3.3. Prevalence of HBV Subtypes/Serotypes. Overall, 5 different subtypes could be identified, namely, "adw2," "adr," "adw3," "ayw2," and "ayw3." All the $4 \mathrm{HBV} / \mathrm{A}$ strains were found to be of subtype "adw2," and the $2 \mathrm{HBV} / \mathrm{C}$ strains were of "adr" subtype. All $3 \mathrm{HBV} / \mathrm{D} 1$ strains were of "ayw2" serotype, while $10 \mathrm{HBV} / \mathrm{D} 2$ strains were of "ayw3" serotype and 1 of "adw3" serotype. In case of all the $27 \mathrm{HBV} / \mathrm{D} 3$ isolates, "ayw3" was found to be the only HBV serotype.

3.4. Analysis of Surface Gene Region. Sequence analysis of the "a" determinant region (amino acid 96-160) of the surface gene revealed that multiple amino acid (aa) substitutions/mutations exist among the OBI cases. At least 4 different genotype/subgenotype unrelated aa mutations are observed: V96A (1/47; 2.13\%), L98V (1/47; 2.13\%), Y100C $(1 / 47 ; 2.13 \%)$, and I1110L (3/47; 6.38\%) (data not shown).

3.5. Analysis of Basal Core Promoter (BCP) and Precore (PreC) Region. BCP region could be successfully amplified and sequenced for 27 samples (which includes $\mathrm{HBV} / \mathrm{A}=4$, $\mathrm{HBV} / \mathrm{C}=1, \mathrm{HBV} / \mathrm{D} 1=2, \mathrm{HBV} / \mathrm{D} 2=8$, and HBV/D3 = 12).
Overall, multiple $\mathrm{BCP}$ and pre-C mutations were found with differential frequency; $1752 \mathrm{C}(4 / 27 ; 14.81 \%)$, only $1753 \mathrm{C}$ (4/27; $14.81 \%), \quad 1753 \mathrm{C}+1762 \mathrm{~T} / 1764 \mathrm{~A} \quad(2 / 27 ; 7.41 \%), \quad 1762 \mathrm{~T} / 1764 \mathrm{~A}$ (2/27; 7.41\%), 1773C (11/27; 40.74\%), 1814C (7/27; 25.93\%), $1858 \mathrm{C}(10 / 27 ; 37.04)$, and $1862 \mathrm{~T}(7 / 27 ; 25.93)$. The frequencies of the BCP and pre-C mutations among the different HBV subgenotypes are shown in Table 2. In case of one HBV/D3 isolate, a small 5 bp deletion (nt 1834-1838) was found.

In none of the isolates, $1766 \mathrm{~T} / 1768 \mathrm{~A}$ double mutation in $\mathrm{BCP}$ region and 1896A/1899A mutations in pre-C region could be detected.

3.6. Analysis of Polymerase Gene Region. The HBV polymerase gene reverse transcriptase $(\mathrm{rt})$ region has been divided into six distinct domains ( $\mathrm{F}$ and $\mathrm{A}-\mathrm{E}$ ). Among these six domains, 5 interdomain regions exist. Among the studied samples, domain A and B were found to be conserved across HBV genotypes and subgenotypes. The variability was observed in the A-B interdomain region. Multiple mutations were found in the A-B interdomain region, such as rtI91L, rtL93P, rtS106C, rtR110G, rtN118T, rtS119T, rtY126H, $\mathrm{rtG127W/R,} \mathrm{rtC136R,} \mathrm{and} \mathrm{rtY158H} \mathrm{(data} \mathrm{not} \mathrm{shown).} \mathrm{Some}$ novel (rtS119T, rtY126H, rtG127W/R, rtC136R, and $\mathrm{rtY} 158 \mathrm{H}$ ) and nonclassical putative (rtI91L) mutations were found.

During analysis, amino acid positions were considered according to the reverse transcriptase domain start site that is, highly conserved "EDWGPCDEHG..." motif [24].

3.7. HBV Quasispecies Analysis. HBV quasispecies study by cloning analysis of the HBV surface gene region was done for 11 randomly chosen OBI isolates. For each isolate, at least 12 clones were amplified, of which at least 10 amplified products were sequenced. During quasispecies analysis, $300 \mathrm{bp}$ partial surface gene sequences were analyzed. Of these 11 isolates, different $\mathrm{HBV}$ subgenotypes were included for analysis ( $\mathrm{HBV} / \mathrm{A}$ $=2 ; \mathrm{HBV} / \mathrm{Cl}=1 ; \mathrm{HBV} / \mathrm{D} 1=1 ; \mathrm{HBV} / \mathrm{D} 2=4$, and $\mathrm{HBV} / \mathrm{D} 3=3$ ).

In none of the isolates, any other minor subpopulation of genotype/subgenotype could be identified. In 3 isolates (3/11; 27.27\%) (2 HBV/D2 and $1 \mathrm{HBV} / \mathrm{D} 1)$, presence of HBV quasispecies was found. The percent nucleotide identity among the subpopulations of these three isolates was $99.6 \pm$ $0.31 ; 99.86 \pm 0.19$; and $99.82 \pm 0.22$, respectively. Of these 3 isolates, 2 were found to have nonsynonymous nucleotide changes at the quasispecies level. In one case, A159G and R160K amino acid changes were found, and in the other, I68T amino acid substitution was observed. Notably, none of these three isolates with the presence of HBV quasispecies were anti-HBs positive.

\section{Discussion}

Transfusion transmitted HBV (TTHBV) still continues to be a major problem in India, despite the availability of the ELISA based HBsAg screening as the only mandatory test for detection of HBV infection in blood units before donations over the last few decades [25]. A previous study reported very high rate of OBI among the voluntary blood donors from Eastern India [1]. In the present study, molecular genetic 


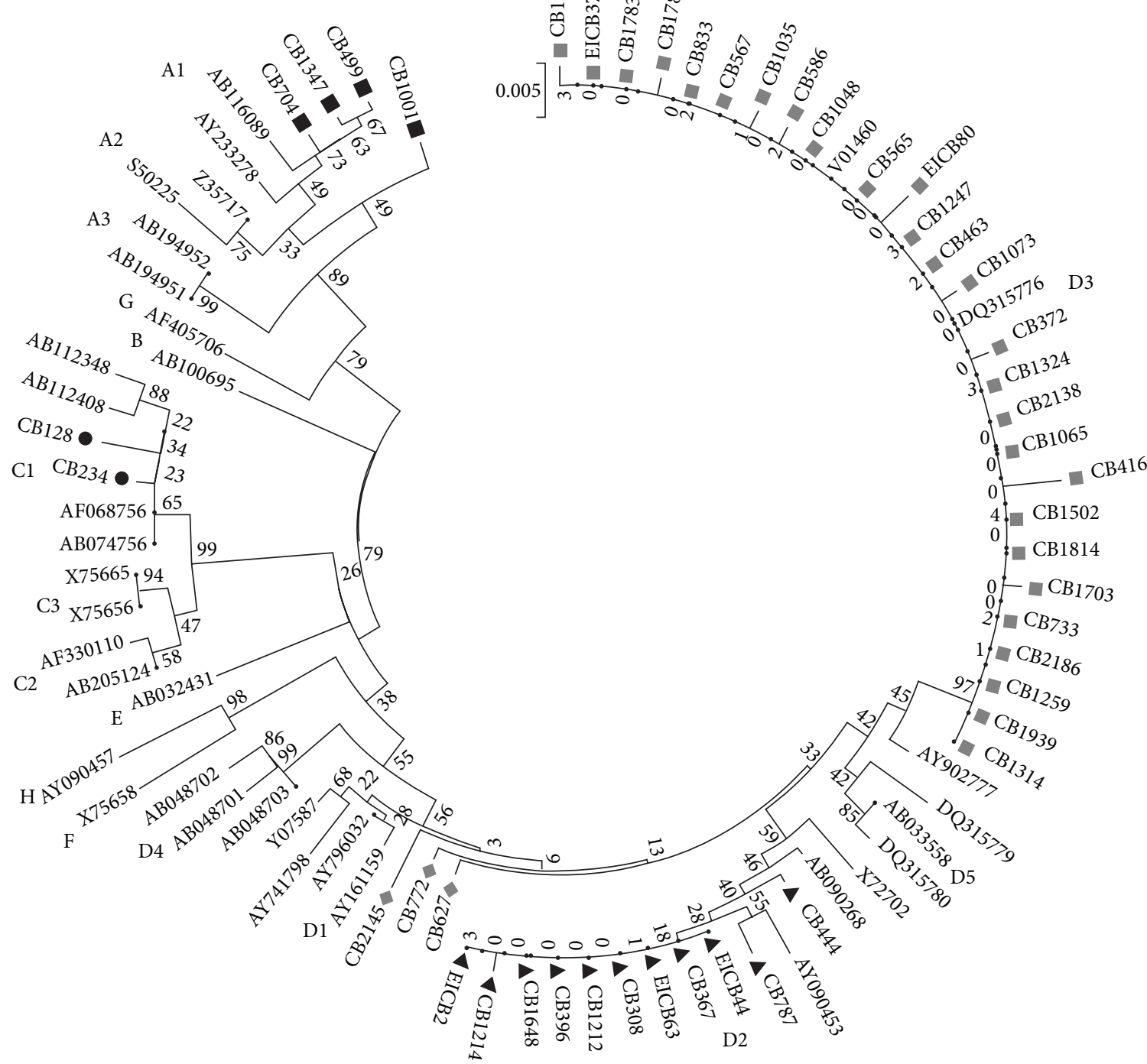

FIGURE 1: Phylogenetic analysis of partial S gene region sequence (300 base pairs) of HBV isolates from Eastern Indian voluntary blood donors with OBI (denoted with "CB"). Different genotypes and subgenotypes are assigned with respect to reference sequences retrieved from the GenBank. The phylogenetic tree was constructed by neighbor joining (NJ) method. The bootstrap values obtained from 1,000 replicates are given at the internal nodes.

characterization of the circulating OBI strains revealed some important facets of HBV infection that are expected to be important from the view point of molecular surveillance. Additionally, this information is valuable for the assessment of clinical potential of these strains.

In this study, viral characterization revealed that HBV/D (87.23\%) was the major strain, while HBV/A (8.51\%) and $\mathrm{HBV} / \mathrm{C}$ (4.26\%) were detected in low proportions (Figure 2). $\mathrm{HBV} / \mathrm{A}$ is reported to be associated with advanced liver disease in the same population [26]; thus, its lower prevalence in the asymptomatic blood donor study population was expected. A previous study reported the predominance of $\mathrm{HBV} / \mathrm{D}$ among the anti-HBc only subjects [27]. Previous studies showed that in eastern India $\mathrm{HBV} / \mathrm{D}$ was associated with asymptomatic/inactive carrier stage $[26,28]$ and HBV/D3 with HBsAg negative carrier state $[19,29]$.
$\mathrm{HBV} / \mathrm{D} 1$ was reported to be associated with $\mathrm{HBs}$ Ag positive infections [19], thus the lower frequency of HBV/D1 among the study subjects was not unusual. Previous studies from the same population reported the presence of HBV/D5 at a considerable level [19]; thus, its absence in the present study population was unusual. In the current study, all the $\mathrm{HBV}$ genotypes/subgenotypes are found to be restricted at the level of HBV serotypes. All the HBV/D3 and HBV/D2 (excepting a single isolate of HBV/D2) are of serotype "ayw3," while $\mathrm{HBV} / \mathrm{A}$ and $\mathrm{HBV} / \mathrm{C}$ were of serotype "adw2" and "adr," respectively.

Interestingly, no particular well known surface gene mutation that can affect the HBsAg detection by ELISA could be detected among the occult HBV strains. Mutations related to diagnostic failure (such as M133T/I, F134N, and S143L) including vaccine escape mutations such as D144A 


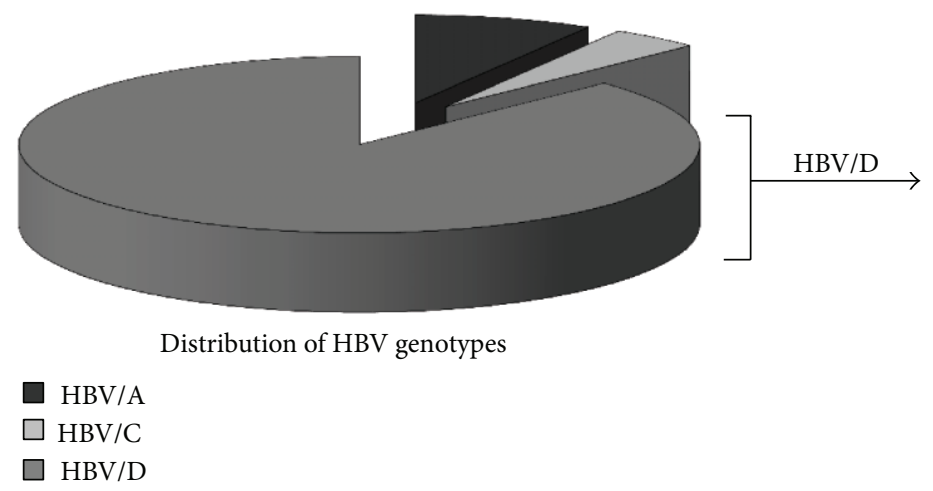

(a)

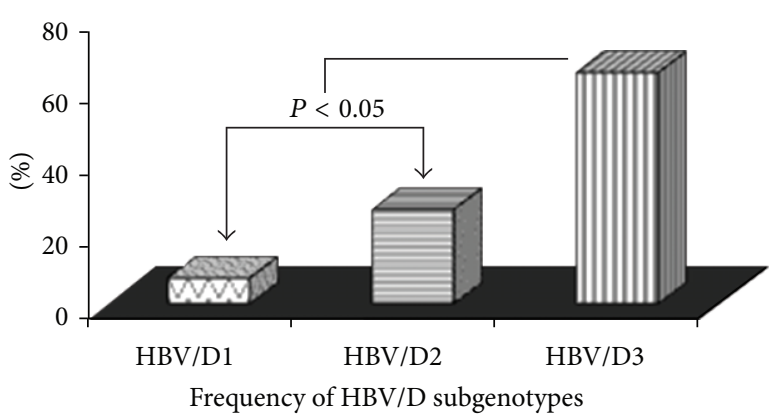

(b)

FIGURE 2: Distribution of HBV genotypes/subgenotypes among the blood donors is represented by pie diagram. The frequencies of different subgenotypes of HBV/D are also depicted. The $P$ value $(<0.05)$ indicates that the prevalence of HBV/D3 was significantly higher in comparison to $\mathrm{HBV} / \mathrm{D} 1$ and HBV/D2.

TABLE 2: Frequency of basal core promoter and precore mutations among the occult HBV isolates.

\begin{tabular}{|c|c|c|c|c|c|}
\hline \multirow{2}{*}{ Mutations (\%) } & \multicolumn{5}{|c|}{ HBV genotypes/subgenotypes } \\
\hline & $\mathrm{HBV} / \mathrm{A} 1(n=4)$ & $\mathrm{HBV} / \mathrm{C} 1(n=1)$ & $\mathrm{HBV} / \mathrm{D} 1(n=2)$ & $\mathrm{HBV} / \mathrm{D} 2(n=8)$ & $\mathrm{HBV} / \mathrm{D} 3(n=12)$ \\
\hline $1752 \mathrm{C}$ & $1(25.0)$ & - & - & $2(25.0)$ & $1(8.3)$ \\
\hline $1753 \mathrm{C}$ & - & $1(100.0)$ & - & $1(12.5)$ & $2(16.6)$ \\
\hline $1762 \mathrm{~T} / 1764 \mathrm{~A}$ & - & - & $1(50.0)$ & - & $1(8.3)$ \\
\hline $1753 \mathrm{C}+1762 \mathrm{~T} / 1764 \mathrm{~A}$ & $1(25.0)$ & - & - & $1(12.5)$ & - \\
\hline $1773 \mathrm{C}$ & $1(25.0)$ & $1(100.0)$ & - & $5(62.5)$ & $4(33.3)$ \\
\hline $1814 \mathrm{C}$ & $1(25.0)$ & - & - & - & $6(50.0)$ \\
\hline $1858 \mathrm{C}$ & $3(75.0)$ & - & - & $1(12.5)$ & $6(50.0)$ \\
\hline $1862 \mathrm{~T}$ & $2(50.0)$ & - & - & - & $5(41.7)$ \\
\hline
\end{tabular}

Notably, 1766T/1768A mutation in BCP region and 1896A or 1899A mutations in pre-C region could not be detected.

and G145R could not be found. Thus, no particular HBsAg structure disrupting mutation related with $\mathrm{HBsAg}$ detection failure could be identified. Notably, T125M substitution was exclusive among the HBV/D3 isolates (data not shown). Similar association of this T125M substitution with HBV/D3 strains was documented in previous studies [18, 29]. When the HBsAg overlapping HBV polymerase region was analyzed, considerable variability was observed in the HBV reverse transcriptase $\mathrm{A}-\mathrm{B}$ interdomain region. In a previous study, we found considerable prevalence of putative mutations among the therapy naive seropositive patients [17]. The clinical and therapeutic significance of the mutations in the HBVrt region among the asymptomatic carriers who are at occult stages of infection need further study.

The clinical impact of OBI is still unclear. In this study, all the OBI subjects are apparently healthy. Thus, for the blood donors who are at the occult stages of infection but are otherwise healthy, HBV associated disease prognosis and transfusion associated HBV transmission are of concern. To assess the clinical consequences of these OBI positive blood donors, prospective longitudinal follow-up studies are needed in future. It has been suggested that immunologically competent individuals with OBI and no other concomitant liver disease generally do not show clinical evidence of liver damage [30]. The average ALT level of the OBI positive cases was $34.67 \pm 8.14 \mathrm{IU} / \mathrm{L}$; thus, no apparent sign of active liver disease was observed. Still, considering the fact that HBV associated disease prognosis is dependent on time and as well as on multiple factors, chances for development of liver complications in future exist. To add to the concern, different clinically relevant mutations in the BCP and polymerase gene region are found among the OBI blood donors in considerable proportions. In the $\mathrm{BCP}$ region mutations such as $1752 \mathrm{C}$, only $1753 \mathrm{C}, 1753 \mathrm{C}+1762 \mathrm{~T} / 1764 \mathrm{~A}$ (triple mutation), and $1762 \mathrm{~T} / 1764 \mathrm{~A}$ (double mutation) are noteworthy, and in $\mathrm{HBV}$ rt region, rtS106C mutation was found among the OBI isolates. A recent study from South India reported the presence of rtS106C mutation among the chronic HBV carriers [31]. Among the HBV/D infected Mongolian population, $1752 \mathrm{C}$ and/or $1753 \mathrm{~V}(\mathrm{~V}=$ non $\mathrm{T})$ mutation was reported to be associated with HCC [32]. Another study showed that $1753 \mathrm{~V}$ mutations in addition to $1762 \mathrm{~T} / 1764 \mathrm{~A}$ are associated with HCC among the HBV/C infected cases [33]. Several studies also suggested the role of mutations at the EnhII/BCP region (1753V and $1762 \mathrm{~T} / 1764 \mathrm{~A})$ with an increased risk of advanced liver diseases [34-36]. Additionally, a recent study from Eastern India showed that among the HBsAg positive subjects $1753 \mathrm{C}$ was common among cirrhosis cases and $1762 \mathrm{~T} / 1764 \mathrm{~A}$ was frequent among chronic liver disease cases and are found to be critical factors for clinical advancement 
[26]. Thus, the presence of these BCP mutations (1752C, $1753 \mathrm{C}, 1753 \mathrm{C}+1762 \mathrm{~T} / 1764 \mathrm{~A}$, and $1762 \mathrm{~T} / 1764 \mathrm{~A}$ ) among the OBI blood donors in the same population is noteworthy. Hence, in the near future, follow-up studies are needed to assess the clinical relevance of these molecular variants among the OBI infected blood donors, as presence of OBI is supposed to be a risk factor for the development of cirrhosis and HCC $[3,37]$.

In case of HBV, presence of $\mathrm{HBV}$ quasispecies is a common phenomenon. In the study samples, $27.27 \%$ (3 out of 11) of the isolates are found to contain HBV quasispecies. Quasispecies diversity within the OBI samples was limited, which was evident by the high level percent nucleotide identity $(99.6 \pm 0.31 ; 99.86 \pm 0.19$ and $99.82 \pm 0.22$ ). Lower quasispecies diversity reflects low level of viral replication rate [38], and this observation was supported by the lower viral load of the OBI samples of this study. Interestingly, in one isolate, a quasispecies clone showed R160K substitution that resulted in serotype conversion, and thus, a unique mixed serotype pattern of infection was documented. In none of the isolates, any immune escape or vaccine escape quasispecies variety could be identified.

One limitation of the current study is the inability of the amplification of all the OBI positive samples for two different HBV genomic regions (HBV surface gene region and $\mathrm{BCP} /$ pre- $\mathrm{C}$ gene region). Some previous studies indicated that due to the structural complexity of the HBV genome, different genetic regions are not amplified with same efficiency in PCR assays [39-42].

Thus, this study highlighted the association of HBV subgenotype D3 with OBI and needs further study to characterize this unique association. The HBV carriers (OBI) bearing clinically relevant $\mathrm{BCP}$ and $\mathrm{HBVrt}$ mutations need regular follow-up to assess the clinical potential of these strains. Hopefully, these data will certainly help to develop better HBV management strategies in India.

\section{Conflict of Interests}

All the authors declare no conflict of interests.

\section{Acknowledgments}

The authors thank all the blood donors for their active and spontaneous participation, as well as all the support staffs of blood banks for their excellent coordination during the study. The project was funded by West Bengal State AIDS Prevention and Control Society. Avik Biswas (Senior Research Fellow) and Rajesh Panigrahi (Senior Research Fellow) received fellowships from Council of Scientific \& Industrial Research (CSIR), New Delhi, and Indian Council of Medical Research (ICMR), New Delhi, respectively.

\section{References}

[1] P. Bhattacharya, P. K. Chandra, S. Datta et al., "Significant increase in HBV, HCV, HIV and syphilis infections among blood donors in West Bengal, Eastern India 2004-2005: exploratory screening reveals high frequency of occult HBV infection," World Journal of Gastroenterology, vol. 13, no. 27, pp. 3730-3733, 2007.

[2] H. Marusawa, S. Uemoto, M. Hijikata et al., "Latent hepatitis $\mathrm{B}$ virus infection in healthy individuals with antibodies to hepatitis B core antigen," Hepatology, vol. 31, no. 2, pp. 488-495, 2000.

[3] Z. N. A. Said, "An overview of occult hepatitis B virus infection," World Journal of Gastroenterology, vol. 17, no. 15, pp. 1927-1938, 2011.

[4] I. Chemin, F. Zoulim, P. Merle et al., "High incidence of hepatitis B infections among chronic hepatitis cases of unknown aetiology," Journal of Hepatology, vol. 34, no. 3, pp. 447-454, 2001.

[5] I. Castillo, E. Rodríguez-Iñigo, J. M. López-Alcorocho, J. Bartolomé, M. Pardo, and V. Carreño, "Comparative study on the clinical and virological characteristics among patients with single occult hepatitis B virus (HBV), single occult hepatitis C virus (HCV) and occult HBV and HCV dual infection," Journal of Medical Virology, vol. 79, no. 3, pp. 236-241, 2007.

[6] H. Norder, A.-M. Couroucé, P. Coursaget et al., "Genetic diversity of hepatitis B virus strains derived worldwide: genotypes, subgenotypes, and HBsAg subtypes," Intervirology, vol. 47, no. 6, pp. 289-309, 2004.

[7] S. Schaefer, "Hepatitis B virus: significance of genotypes," Journal of Viral Hepatitis, vol. 12, no. 2, pp. 111-124, 2005.

[8] C. M. Olinger, P. Jutavijittum, J. M. Hübschen et al., "Possible new hepatitis B virus genotype, southeast Asia," Emerging Infectious Diseases, vol. 14, no. 11, pp. 1777-1780, 2008.

[9] T. T. T. Huy, T. N. Trinh, and K. Abe, "New complex recombinant genotype of hepatitis B virus identified in Vietnam," Journal of Virology, vol. 82, no. 11, pp. 5657-5663, 2008.

[10] K. Tatematsu, Y. Tanaka, F. Kurbanov et al., "A genetic variant of hepatitis B virus divergent from known human and ape genotypes isolated from a Japanese patient and provisionally assigned to new genotype J," Journal of Virology, vol. 83, no. 20, pp. 10538-10547, 2009.

[11] C. Chu, M. Hussain, and A. S. F. Lok, "Hepatitis B virus genotype $\mathrm{B}$ is associated with earlier $\mathrm{HBeAg}$ seroconversion compared with hepatitis B virus genotype C," Gastroenterology, vol. 122, no. 7, pp. 1756-1762, 2002.

[12] A. Kramvis and M. C. Kew, "Relationship of genotypes of hepatitis $B$ virus to mutations, disease progression and response to antiviral therapy," Journal of Viral Hepatitis, vol. 12, no. 5, pp. 456-464, 2005.

[13] A. Kay and F. Zoulim, "Hepatitis B virus genetic variability and evolution," Virus Research, vol. 127, no. 2, pp. 164-176, 2007.

[14] S.-Y. Kuang, P. E. Jackson, J.-B. Wang et al., "Specific mutations of hepatitis B virus in plasma predict liver cancer development," Proceedings of the National Academy of Sciences of the United States of America, vol. 101, no. 10, pp. 3575-3580, 2004.

[15] F. Ntziora, D. Paraskevis, C. Haida et al., "Quantitative detection of the M204V hepatitis B virus minor variants by amplification refractory mutation system real-time PCR combined with molecular beacon technology," Journal of Clinical Microbiology, vol. 47, no. 8, pp. 2544-2550, 2009.

[16] R. Pastor, F. Habersetzer, S. Fafi-Kremer et al., "Hepatitis B virus mutations potentially conferring adefovir/tenofovir resistance in treatment-naive patients," World Journal of Gastroenterology, vol. 15, no. 6, pp. 753-755, 2009.

[17] R. Panigrahi, A. Biswas, B. K. De, S. Chakrabarti, and R. Chakravarty, "Characterization of antiviral resistance mutations among the Eastern Indian Hepatitis B virus infected population," Virology Journal, vol. 10, article 56, 2013. 
[18] R. Panigrahi, A. Biswas, S. Datta et al., "Anti-hepatitis B core antigen testing with detection and characterization of occult hepatitis B virus by an in-house nucleic acid testing among blood donors in Behrampur, Ganjam, Orissa in southeastern India: implications for transfusion," Virology Journal, vol. 7, article 204, 2010.

[19] P. K. Chandra, A. Biswas, S. Datta et al., "Subgenotypes of hepatitis B virus genotype D (D1, D2, D3 and D5) in India: differential pattern of mutations, liver injury and occult HBV infection," Journal of Viral Hepatitis, vol. 16, no. 10, pp. 749-756, 2009.

[20] A. Banerjee, S. Banerjee, A. Chowdhury et al., "Nucleic acid sequence analysis of basal core promoter/precore/core region of hepatitis B virus isolated from chronic carriers of the virus from kolkata, eastern india: low frequency of mutation in the precore region," Intervirology, vol. 48, no. 6, pp. 389-399, 2005.

[21] S. Kwok and R. Higuchi, "Avoiding false positives with PCR," Nature, vol. 339, no. 6221, pp. 237-238, 1989.

[22] S. Datta, R. Panigrahi, A. Biswas et al., "Genetic characterization of hepatitis B virus in peripheral blood leukocytes: evidence for selection and compartmentalization of viral variants with the immune escape G145R mutation," Journal of Virology, vol. 83, no. 19, pp. 9983-9992, 2009.

[23] T. A. Hall, "BioEdit: a user-friendly biological sequence alignment editor and analysis program for Windows 95/98/NT," Nucleic Acids Symposium Series, vol. 41, no. 7, pp. 95-98, 1999.

[24] L. J. Stuyver, S. A. Locarnini, A. Lok et al., "Nomenclature for antiviral-resistant human hepatitis B virus mutations in the polymerase region," Hepatology, vol. 33, no. 3, pp. 751-757, 2001.

[25] H. K. Dhawan, N. Marwaha, R. R. Sharma et al., "Anti-HBc screening in Indian blood donors: still an unresolved issue," World Journal of Gastroenterology, vol. 14, no. 34, pp. 5327-5330, 2008.

[26] A. Biswas, A. Banerjee, P. K. Chandra et al., "Variations in the functional domain of basal core promoter of hepatitis B virus among Eastern Indian patients with prevalence of genotypes A, $\mathrm{C}$, and D among the same ethnic population," Journal of Medical Virology, vol. 83, no. 2, pp. 253-260, 2011.

[27] K. M. Weinberger, T. Bauer, S. Böhm, and W. Jilg, "High genetic variability of the group-specific a-determinant of hepatitis B virus surface antigen (HBsAg) and the corresponding fragment of the viral polymerase in chronic virus carriers lacking detectable HBsAg in serum," Journal of General Virology, vol. 81, no. 5, pp. 1165-1174, 2000.

[28] S. Datta, A. Biswas, P. K. Chandra et al., "Molecular epidemiology and clinical significance of hepatitis B virus genotypes, core promoter and precore mutations in Eastern India," Intervirology, vol. 51, no. 4, pp. 275-284, 2008.

[29] A. Banerjee, P. K. Chandra, S. Datta et al., "Frequency and significance of hepatitis B virus surface gene variant circulating among 'antiHBc only' individuals in Eastern India," Journal of Clinical Virology, vol. 40, no. 4, pp. 312-317, 2007.

[30] M. Romero, A. Madejón, C. Fernández-Rodríguez, and J. García-Samaniego, "Clinical significance of occult hepatitis B virus infection," World Journal of Gastroenterology, vol. 17, no. 12, pp. 1549-1552, 2011.

[31] A. M. Ismail, P. Samuel, C. E. Eapen, R. Kannangai, and P. Abraham, "Antiviral resistance mutations and genotypeassociated amino acid substitutions in treatment-Naïve Hepatitis B virus-infected individuals from the Indian subcontinent," Intervirology, vol. 55, no. 1, pp. 36-44, 2012.
[32] A. Elkady, Y. Tanaka, F. Kurbanov, T. Oynsuren, and M. Mizokami, "Virological and clinical implication of core promoter C1752/V1753 and T1764/G1766 mutations in hepatitis B virus genotype D infection in Mongolia," Journal of Gastroenterology and Hepatology, vol. 23, no. 3, pp. 474-481, 2008.

[33] Y. Tanaka, M. Mukaide, E. Orito et al., "Specific mutations in enhancer II/core promoter of hepatitis B virus subgenotypes $\mathrm{C} 1 / \mathrm{C} 2$ increase the risk of hepatocellular carcinoma," Journal of Hepatology, vol. 45, no. 5, pp. 646-653, 2006.

[34] X. Guo, Y. Jin, G. Qian, and H. Tu, "Sequential accumulation of the mutations in core promoter of hepatitis $B$ virus is associated with the development of hepatocellular carcinoma in Qidong, China," Journal of Hepatology, vol. 49, no. 5, pp. 718-725, 2008.

[35] Y.-C. Chou, M.-W. Yu, C.-F. Wu et al., “Temporal relationship between hepatitis B virus enhancer II/basal core promoter sequence variation and risk of hepatocellular carcinoma," Gut, vol. 57, no. 1, pp. 91-97, 2008.

[36] J. J. Y. Sung, S. K. W. Tsui, C.-H. Tse et al., "Genotype-specific genomic markers associated with primary hepatomas, based on complete genomic sequencing of hepatitis B virus," Journal of Virology, vol. 82, no. 7, pp. 3604-3611, 2008.

[37] I. Chemin and C. Trépo, "Clinical impact of occult HBV infections," Journal of Clinical Virology, vol. 34, supplement 1, pp. S15-S21, 2005.

[38] A. Zahn, C. Li, K. Danso et al., "Molecular characterization of occult hepatitis B virus in genotype E-infected subjects," Journal of General Virology, vol. 89, no. 2, pp. 409-418, 2008.

[39] M. Umeda, H. Marusawa, H. Seno et al., "Hepatitis B virus infection in lymphatic tissues in inactive hepatitis B carriers," Journal of Hepatology, vol. 42, no. 6, pp. 806-812, 2005.

[40] Y. Murakami, M. Minami, Y. Daimon, and T. Okanoue, "Hepatitis B virus DNA in liver, serum, and peripheral blood mononuclear cells after the clearance of serum hepatitis B virus surface antigen," Journal of Medical Virology, vol. 72, no. 2, pp. 203-214, 2004.

[41] R. Ramesh, S. K. Panda, S. Jameel, and P. Rajasambandam, "Mapping of the hepatitis B virus genome in hepatocellular carcinoma using PCR and demonstration of a potential transactivator encoded by the frequently detected fragment," Journal of General Virology, vol. 75, no. 2, pp. 327-334, 1994.

[42] M. Cabrerizo, J. Bartolomé, C. Caramelo, G. Barril, and V. Carreño, "Molecular analysis of hepatitis B virus DNA in serum and peripheral blood mononuclear cells from hepatitis B surface antigen-negative cases," Hepatology, vol. 32, no. 1, pp. $116-123,2000$. 


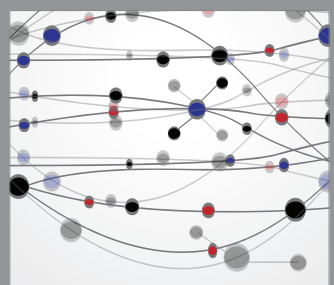

The Scientific World Journal
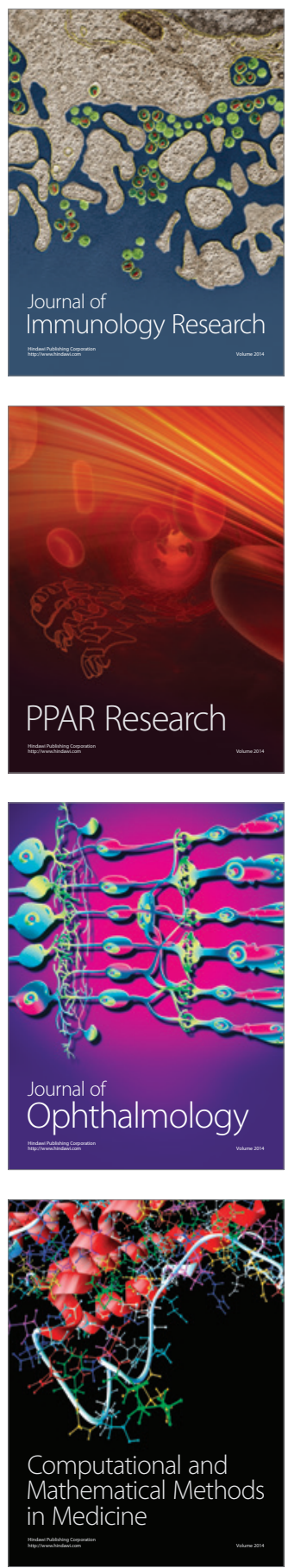

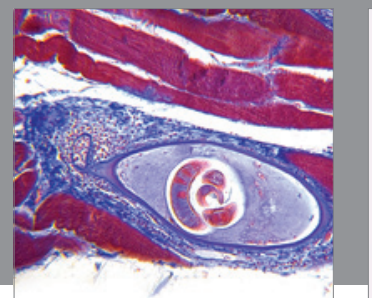

Gastroenterology

Research and Practice
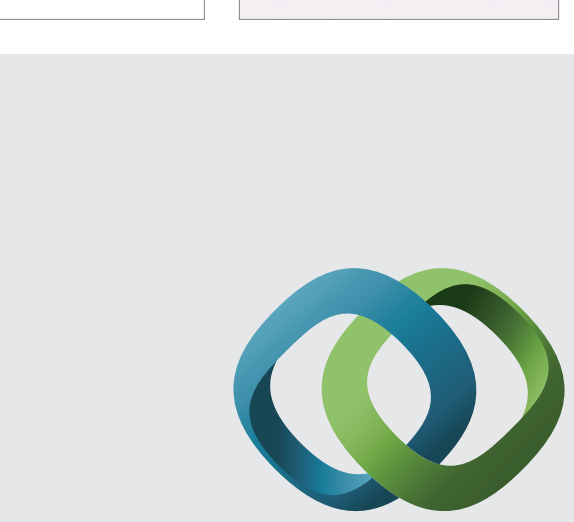

\section{Hindawi}

Submit your manuscripts at

http://www.hindawi.com
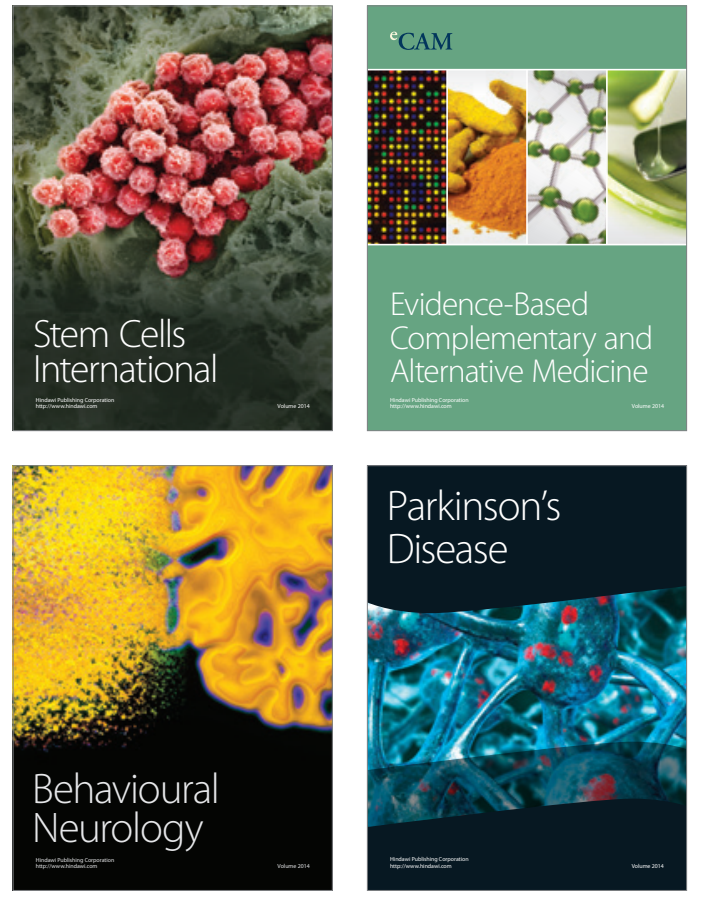
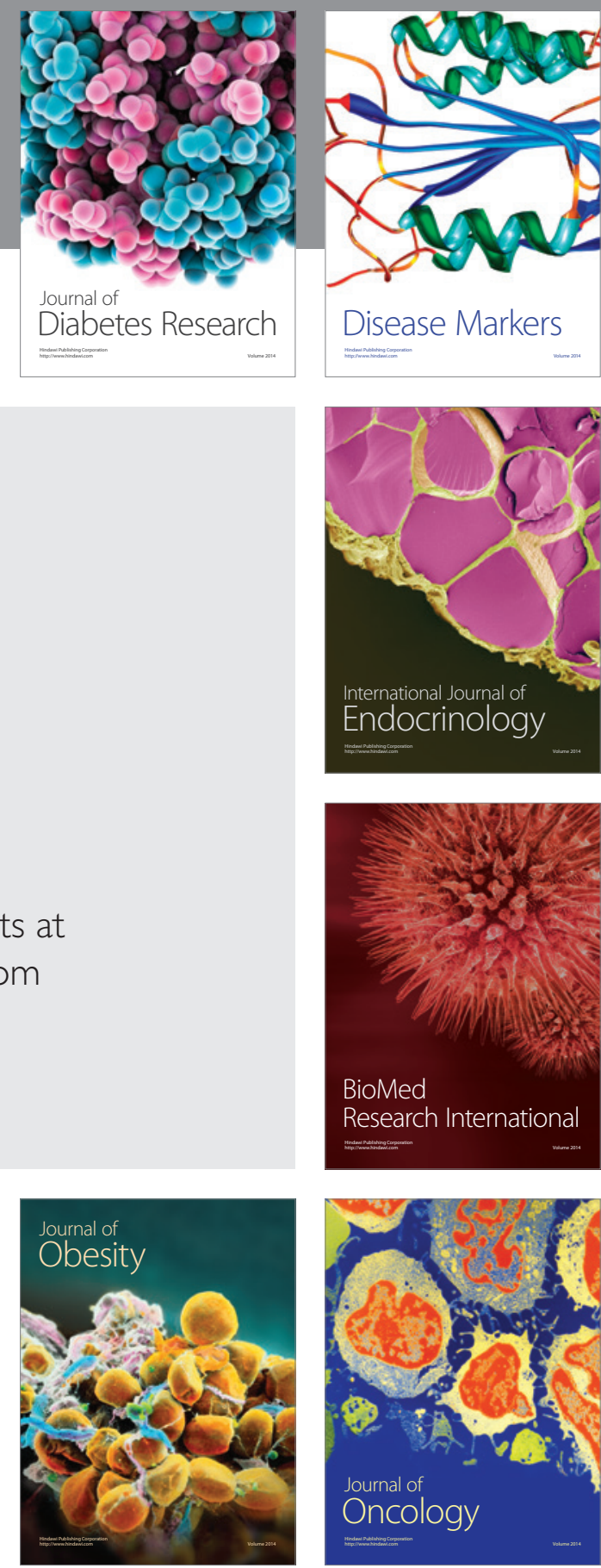

Disease Markers
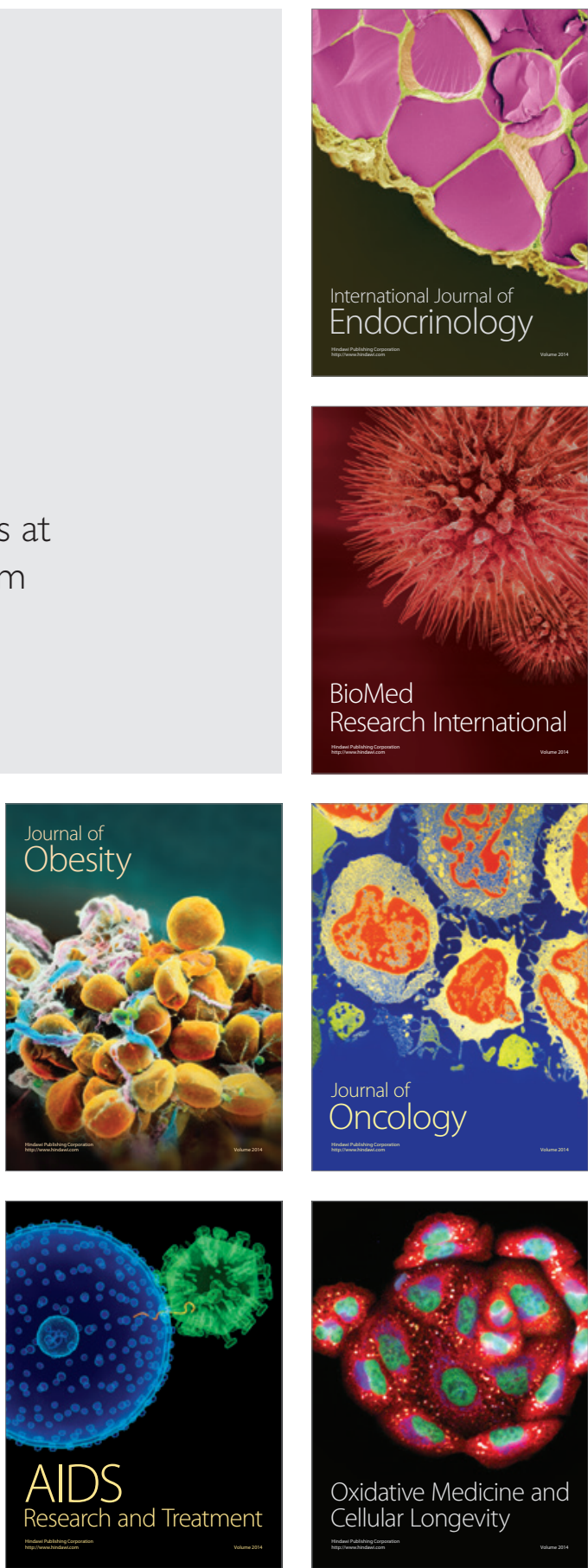